Journal of Animal and Veterinary Advances 11 (19): 3506-3511, 2012

ISSN: $1680-5593$

(C) Medwell Journals, 2012

\title{
Distribution and Age-Related Changes in Somatostatin-Immunopositive Cell in the Small Intestinal of African Ostrich Chicks
}

\author{
${ }^{1,2}$ Chen Min, ${ }^{1}$ Wang Lei, ${ }^{1}$ T.T. Liu, ${ }^{1}$ Song Hui, ${ }^{1}$ H.Z. Liu and ${ }^{1}$ K.M. Peng \\ ${ }^{1}$ College of Animal Science and Veterinary Medicine, Huazhong Agricultural University, \\ 430070 Wuhan, Hubei, P.R. China \\ ${ }^{2}$ Xinyang Agricultural College, 464000 Xinyang, Henan, P.R. China
}

\begin{abstract}
The present study was performed to investigate the morphology and topographic distribution, developmental changes of somatostatin-producing cells in the small intestinal of African ostrich chicks at different ages: 1 day (birth), 45 days, 90 (days) and 334 (control). The results were as follows: Somatostatin (SOM) cells were present in the mucosal layer of whole small intestinal of the African ostrich on all checked days. SOM cells had round and spherical shapes (closed-type cells) or spindle and pyriform shapes (open-type cells). SOM cells were localized preferentially in the duodenum of 90 days old ostrich. The quantity of SOM-IP cells increased gradually after birth until 90 days and peaked on 90 days in the duodenum, meanwhile it decreased gradually after birth until 90 days and footed on 90 days in the jejunal and ileal regions. These results indicated that SOM might be involved in functional and developmental regulation of small intestinal of African ostrich chicks.
\end{abstract}

Key words: Somatostatin, African ostrich, small intestinal, immunohistochemistry, chicks, birth

\section{INTRODUTION}

Somatostatin (SOM) was discovered firstly in the ovine hypothalamus as a regulatory peptide that inhibited the secretion of growth hormone (Brazeau et al., 1973). Afterwards, growing researches suggestted that SOM-positive cells were distributed not only in the hypothalamus but also widely throughout the central nervous system and in most major peripheral organs including the gastrointestinal tract, pancreas, heart, eye, thyroid, thymus and skin (Patel and Reichlin, 1978; Polak and Bloom, 1986; Patel, 1999; Vockel et al., 2011). SOM acted in two biologically active forms, SOM-14 and SOM-28 consisting of 14 and 28 amino acids. The entire SOM-14 sequence was present in the C-terminus of SOM-28. It was generally assumed that SOM-14 was the predominant biologically active form (Patel, 1999). SOM was involved in regulation of neuronal function, hormonal secretion, the immune response, cardiovascular function, gut exocrine secretion and motor activity (Polak and Bloom, 1986; Ferone et al., 2004; Viollet et al., 2008; Ben-Shlomo and Melmed, 2010). Moreover, Somatostatin Immunoreactivity (SOM-IP) had been found throughout the gastrointestinal tract in all species examined and SOM concentration was higher relatively in the gastrointestinal tract in most species (King and Millar, 1979) which indicated SOM played a pivotal role in the gastrointestinal tract. Distribution of SOM had been reported in the gastrointestinal tract of many species including frog, fish, chicken, rat, ruminants, pigeon, horse and camel (Darvodelsky et al., 1988; Saito et al., 1989; Yamanaka et al., 1989; Ali et al., 2007; Gahete et al., 2010). However, there had been no studies on the distribution and function of SOM in the gastrointestinal tract of African ostrich. Therefore, the aim of the present study was performed to examine the distribution and morphological characteristics and developmental changes of SOM cells in the small intestine for a better understanding of the physiological role of SOM in African ostrich gut. Moreover, comparative analysis of distribution of SOM in the different animals would enhance the understanding of its paradigmatic evolutionary complexity and functional versatility.

\section{MATERIALS AND METHODS}

Tissue preparation: African ostrich chicks (24 females) were purchased from a standard ostrich farm in

Corresponding Author: K.M. Peng, College of Animal Science and Veterinary Medicine, Huazhong Agricultural University, 430070 Wuhan, Hubei, P.R. China 
Guangdong province, China on postnatal day 1 (at birth) and were transported subsequently to a battery house where feed and water were available abondon. All of the birds were maintained in a heated room with slatted plastic flooring and were fed a starter diet for postnatal days 1-334. On postnatal days $1,45,90$ and 334 (control group), the birds $(n=4)$ were deeply anesthetized with $10 \%$ urethane (Caoyang Secondary Chemical Plant, Shanghai, China) and perfused, initially with $1000 \mathrm{~mL}$ of $0.85 \%$ normal saline (containing $0.075 \%$ sodium citrate) and thereafter with $1500 \mathrm{~mL}$ of $4 \%$ paraformaldehyde phosphate-buffered solution $\left(0.1 \mathrm{~mol} \mathrm{~L}^{-1}, \mathrm{pH} 7.4\right)$ at $4^{\circ} \mathrm{C}$. The abdomen was cut open. Segments of their small intestinal approximately $1 \mathrm{~cm}$ in length were quickly removed and opened along their longitudinal axes. The segments were postfixed in neutrally buffered formaldehyde for $24 \mathrm{~h}$. All tissues were routinely dehydrated in an ethanol series and subsequently embedded in paraffin.

Immunohistochemistry experiments: For SOM staining, paraffin-embedded small intestinal were sectioned and de-waxed with xylene and rehydrated through graded alcohols to distilled water then treated with $3 \%$ hydrogen peroxide $\left(\mathrm{H}_{2} \mathrm{O}_{2}\right)$ to quench endogenous peroxidase for $10 \mathrm{~min}$ at room temperature. The sections were washed with distilled water and incubated with a $\mathrm{pH} 6.0$ citrate buffer and placed in a microwave oven until the water boiled for antigen retrieval. After rinsing with PBS, nonspecific binding sites were blocked with $10 \%$ normal goat serum for $20 \mathrm{~min}$. Afterwards, the samples were incubated with rabbit polyclonal anti-SOM antiserum diluted 1:200 in PBS (BA0124, Boster Corporation, China) for $2 \mathrm{~h}$ in a humid chamber at $37^{\circ} \mathrm{C}$. After washing with PBS for $6 \mathrm{~min}$, for detection of the primary antibody, the slides were incubated for $40 \mathrm{~min}$ at room temperature with biotin-conjugated anti-rabbit Ig G serum (SA1022; Boster). Followed by further washing with PBS, the sections were incubated for $30 \mathrm{~min}$ with an SABC solution prepared according to the manufacturer's instructions. Following another washing step in PBS, SOM was visualized using diaminobenzidine-tetrachloride kit (DAB kit, AR1022) for $5 \mathrm{~min}$. After washing with distilled water, the sections were dehydrated with a graded ethanol series, cleared in xylene, mounted with a coverslip and viewed under a light microscope (BH-2; Olympus, Japan). Control sections were performed using the same method, omitting the primary antibody. The specificity of the immunostaining was tested by pre-absorbtion of the affinity purified anti-SOM antiseru with $10 \mu \mathrm{M}$ of the respective peptide, for $2-3 \mathrm{~h}$ at $37^{\circ} \mathrm{C}$. Following centrifugation for $10 \mathrm{~min}$ at $13,000 \mathrm{rpm}$, serial sections were incubated with the preabsorbed serum.

SOM cells count and statistical analysis: Five serial sections were examined by light microscopy on the preparations obtained from each animal. In each section, the number of MCs in different areas in 10 high-power fields selected at random were counted and the arithmetic mean was calculated. Results were expressed as means \pm Standard Errors on the mean (means $\pm \mathrm{SE}$ ). Statistical analysis was done using analysis of variance statistics software with Duncan's multiple range test where appropriate. Differences of $\mathrm{p}<0.05$ were considered significant.

\section{RESULTS AND DISCUSSION}

Distribution and morphometric analysis of SOM-IP cells: The present study demonstrated the characteristic distribution of SOM-IP endocrine cells whereas immunoreactivity for the peptide in the nervous system was not revealed. SOM-IP cells were present in the mucosal layer of whole small intestinal on all checked day of the African ostrich. About 90 days old female African ostriches were used to observed the distribution of SOM-IP cells in the small intestinal (Fig. 1a-i). In the small intestine, SOM-IP cells were moderate in number in the duodenal portion but then became few in the jejunal and ileal portions (Fig. 1a, f and h). SOM-IP cells were present in the crypts and villi which often had round and spherical shapes (closed-type cells, Fig. 1c and d arrows show). Spindle and pyriform shaped cells having contact with the lumen via the apical cytoplasmic process (open-type cells, Fig. 1c and d triangles show) were also found. Therefore, the SOM-IP cells showed the characteristic forms of both open and close types in the small intestinal of African ostriches. In general, closedtypes cells were more relative than open-types cells in number. In the villus, SOM-IP cells were mainly located in epithelia. Morphometric analysis revealed that SOM-IP cells were localized preferentially in the duodenum and the cell density gradually decreased from the former to latter segment $(\mathrm{p}<0.05)$ (Fig. 2).

Developmental changes in SOM-IP cells in the African ostrich small intestine: The present study revealed the quantity of SOM-IP cells varied from postnatal day 1 in the different regions of African ostrich small intestine. The quantity of SOM-IP cells increased gradually after 


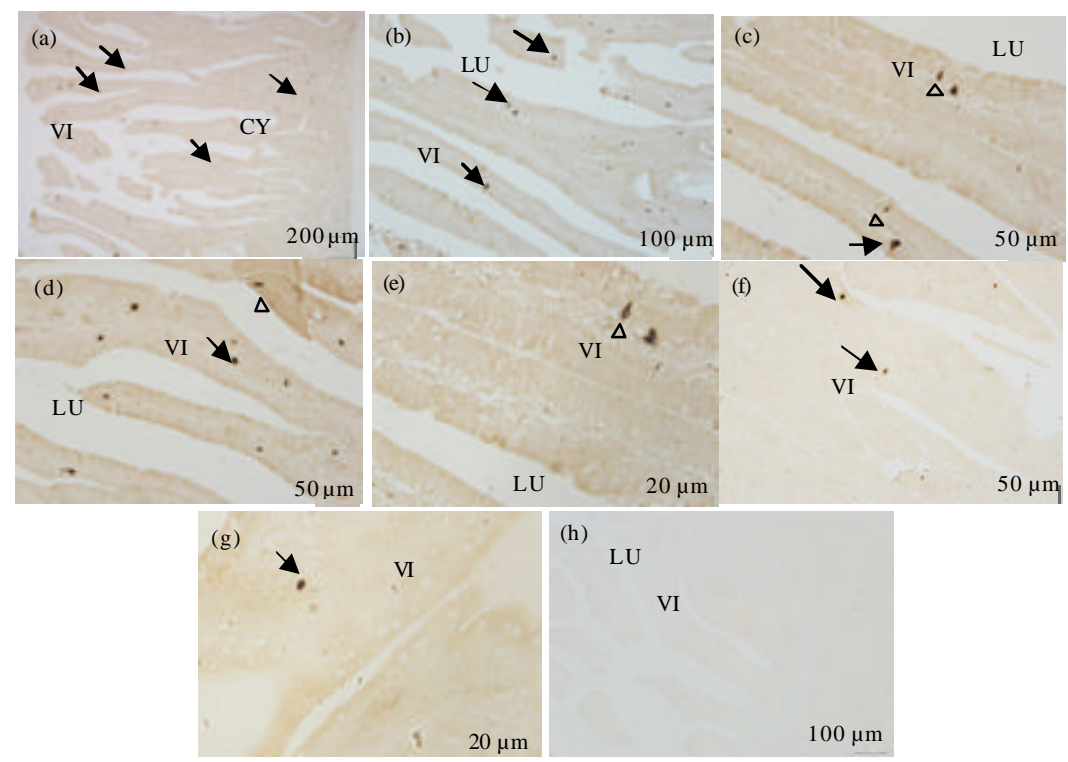

Fig. 1: Distribution patterns of SOM-immunopositive cells in the small intestinal of African ostrich chicks at 90 days. a, b) Large amounts of SOM cells (arrows) were found in the duodenum and chiefly located adjacent to the epithelium; c-e) Eimmunopositive cells (arrows or triangles) were observed in the duodenum. Closed-type cells had round and spherical shapes (arrows). Open-type cells had spindle and pyriform shapes contacting with the lumen via the apical cytoplasmic process (triangles); $\mathrm{f}, \mathrm{g}$ ) SOM-immunopositive cells (arrows or triangles) were found in the jejunum; h, i) SOM-immunopositive cells (arrows or triangles) were found in the ileum; j) Microphotograph of absorption testing in the ileum. No positive cells were found in the mucosa of the ileum (VI: Villi; CY: Crypt; LU: Lumen)

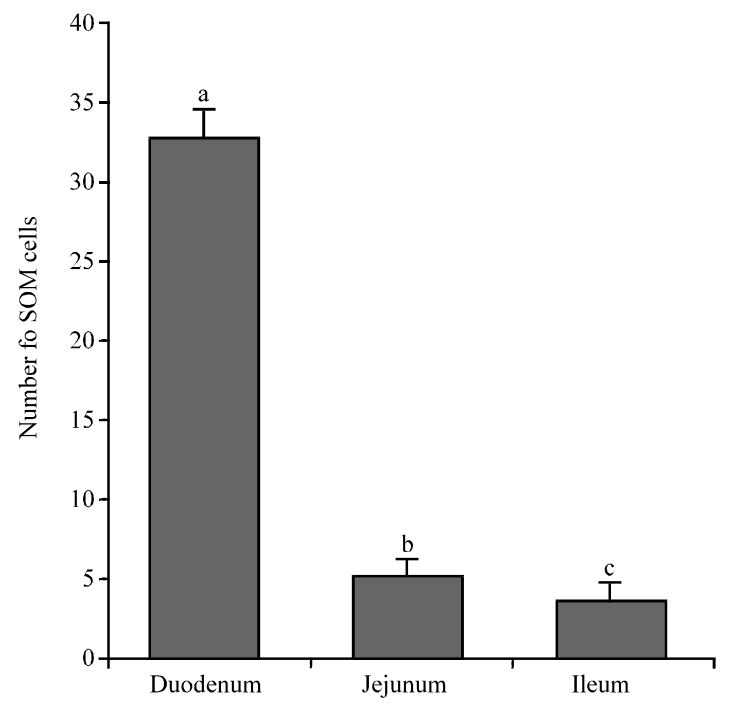

Fig. 2: Histogram showing the number of SOM cells in the 90 day old African ostrich small intestinal. SOM-immunopositive cells were presented throughout the small intestinal mucosa. ${ }^{\mathrm{a}-c}$ Different letters within the same column indicated significant differences among segments according to Duncan's multiple range $(\mathrm{p} \leq 0.05)$
Table 1: The number of SOM-IP cells in small intestinal of African ostrich on postnatal days $1,45,90$ and 334

\begin{tabular}{lccr}
\hline \multicolumn{4}{c}{ on postnatal days $1,45,90$ and 334} \\
& Number of SOM cells & \\
Days & Duodenum & Jejunum & Ileum \\
\hline 1 & $6.25 \pm 1.25^{\mathrm{c}}$ & $22.60 \pm 2.77^{\mathrm{a}}$ & $19.00 \pm 2.10^{\mathrm{a}}$ \\
45 & $13.35 \pm 2.54^{\mathrm{b}}$ & $9.90 \pm 1.71^{\mathrm{b}}$ & $9.05 \pm 1.79^{\mathrm{b}}$ \\
90 & $32.55 \pm 1.96^{\mathrm{a}}$ & $5.15 \pm 1.18^{\mathrm{c}}$ & $3.70 \pm 1.13^{\mathrm{c}}$ \\
334 & $32.10 \pm 1.94^{\mathrm{a}}$ & $4.90 \pm 1.29^{\mathrm{c}}$ & $3.55 \pm 0.89^{\mathrm{c}}$ \\
\hline All of the data are expressed as means \pm SE. ${ }^{\text {ac } D i f f e r e n t ~ l e t t e r s ~ w i t h i n ~ t h e ~ s a m e ~}$ \\
column indicated significant differences among ages according to Duncan's \\
multiple range ( $\mathrm{p} \leq 0.05$ )
\end{tabular}

birth until 90 days and peaked on 90 days in the duodenum (Fig. 3, Table 1). In contrast, the number of SOM-IP cells decreased gradually after birth until 90 days and footed on 90 days in the jejunal and ileal regions (Fig. 4, Table 1).

Studies on the distribution of SOM cells had been performed in the small intestinal of the many species. In the one-humped camel, SOM cells were found in all areas of the small intestine, with higher density in the crypts than in the villi (Ali et al., 2007). In turtle, SOM cells were observed in the basal portion of the epithelia of small intestinal with a spindle to spherical shape ( $\mathrm{Ku}$ et al., 2001). In frog, scattered SOM cells occurred in all regions of the small intestinal with number of these cells 


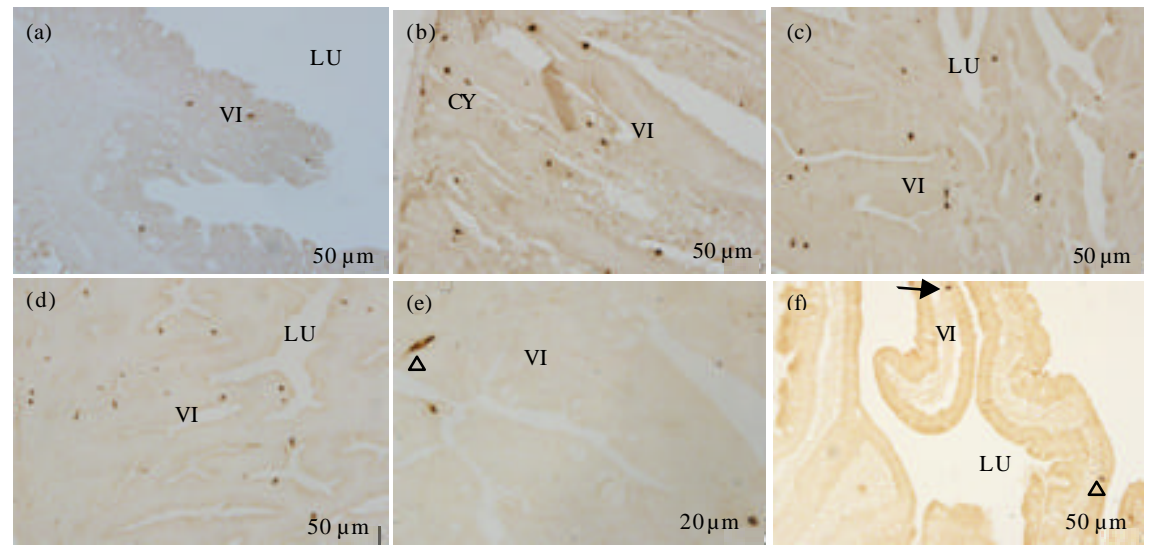

Fig. 3: Representative photomicrograph showing the villi in theduodenum of African ostrich on postnatal days 1, 45, 90 and 334 (Stained with immunohistochemistry). SOM-IP cell (arrows) could be observed at every time point. Panels a-d correspond to days 1, 45, 90 and 334, respectively. VI: Villi (a-d); Bar: $50 \mu \mathrm{m}$
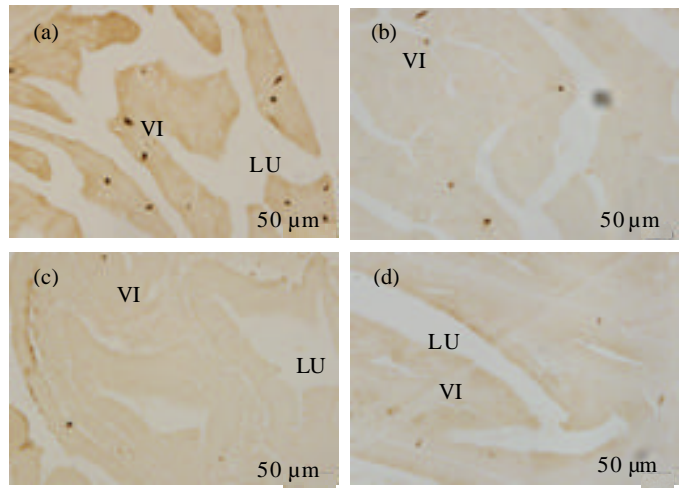

Fig. 4: Representative photomicrograph showing the villi in the jejunum of African ostrich on postnatal days $1,45,90$ and 334 (Stained with immunohistochemistry). SOM-IP cell (arrows) could be observed at every time point. Panels a-d correspond to days $1,45,90$ and 334, respectively. VI: Villi (a-d); Bar: $50 \mu \mathrm{m}$

decreasing gradually in the oral to anal direction (Trandaburu and Numberger, 1995). In chicken, A few SOM cells were detected in the duodenum and jejunum, and SOM cells were mainly distributed around intestinal glands and between the epithelial cells in the duodenum (Yamanaka et al., 1989; Yang et al., 2007). In the present study, the regional distributions of SOM-IP cells were investigated in African ostrich small intestine at different ages for the first time using immunohistochemical techniques. Similar to these reports in other species, SOM-IP cells were found in the African ostrich small intestinal mucosa. SOM-IP cells were present in crypts and villi which showed the characteristic form of both open and close types. SOM-IP cells were localized preferentially in the duodenum and the cell density gradually decreased from the former to latter segment in the small intestinal.

Endocrine cells dispersed in the gastrointestinal tract comprised the largest endocrine organ of the body. It was composed of $>20$ different cell populations. These gastrointestinal endocrine cells synthesized and released various types of gastrointestinal hormones to regulate the digestive system (Pyarokhil et al., 2012). While SOM inhibited the release of virtually every gut hormone that had been tested. It had a generalized inhibitory effect on gut exocrine secretion and suppressed motor activity generally as well as through inhibition of gastric emptying, gallbladder contraction and small intestinal segmentation (Barnett, 2003; Van Op den Bosch et al., 2009). So, the present study provided morphological evidences that SOM might play important action in small intestinal of African ostrich, cooperating with the other hormone produced by gastrointestinal endocrine cells. Moreover, the presence of these two SOM cell types in the small intestinal suggestted that SOM regulated the physiological functions of small intestinal in African ostrich in many ways.

In addition, the interesting result obtained in the present study was with regard to the different changes of the number of SOM-IP cells in different regions. The present study displayed that the quantity of SOM-IP cells increased gradually after birth until 90 days and peaked on 90 day in the duodenum while it decreased gradually after birth until 90 days and footed on 90 day in the jejunal and ileal regions. Wang reported (Wang and Peng, 2008) that the days $1-90$ was an important period of development of the African ostrich small intestinal, during 
the period there were significant changes in relative weight and histological structure of small intestinal. Furthermore, the present study showed that there was a significant change in the number of SOM cells during the period which suggestted SOM possibly participated in regulating development of the African ostrich small intestinal. However, the further study would be needed to research the mechanism of different changes in the number of SOM cells in different segments of small intestinal.

\section{CONCLUSION}

The present study showed that SOM were distributed in the African ostrich chicken small intestinal at different stage. Furthermore, the number of SOM in different regions of small intestinal changed differently within brood time. These findings indicated that SOM possibly played intricate regulating action in function and development of small intestinal of African ostrich chicken.

\section{ACKNOWLEDGEMENTS}

Researchers would like to thank Dr. Wang JiaXiang of College of Animal Science and Veterinary Medicine, Yangtze University for her help on the experiments. This study was supported by the National Natural Science Foundation Project of China, No. 30972152.

\section{REFERENCES}

Ali, M.A., F. Nyberg, S.I. Chandranath, S. Dhanasekaran and S. Tariq et al., 2007. Distribution of neuroendocrine cells in the small and large intestines of the one-humped camel (Camelus dromedarius). Neuropeptides, 41: 293-299.

Barnett, P., 2003. Somatostatin and somatostatin receptor physiology. Endocrine, 20: 255-264.

Ben-Shlomo, A. and S. Melmed, 2010. Pituitary somatostatin receptor signaling. Trends Endocrinol. Metab., 21: 123-133.

Brazeau, P., W. Vale, R. Burgus, N. Ling, M. Butcher, J. Rivier and R. Guillemin, 1973. Hypothalamic polypeptide that inhibits the secretion of immunoreactive pituitary growth hormone. Science, 179: 77-79.

Darvodelsky A.M., M.W. Davey, A.M. Reid, D.A. Titchen and X.Wang, 1988. Immunochemical characterisation of somatostatin in ruminants. Regul. Pept., 20: 161-170.
Ferone D., P.M. Van Hagen, C. Semino, V.A. Dalm and A. Barreca et al., 2004. Somatostatin receptor distribution and function in immune system. Dig. Liver Dis., 36: 68-77.

Gahete M.D., J. Cordoba-Chacon, M. Duran-Prado, M.M. Malagon and A.J. Martinez-Fuentes et al., 2010. Somatostatin and its receptors from fish to mammals. Ann. N.Y. Acad. Sci., 1200: 43-52.

King, J.A. and R.P. Millar, 1979. Phylogenetic and anatomical distribution of somatostatin in vertebrates. Endocrinology, 105: 1322-1329.

Ku, S.K., H.S. Lee, J.H. Lee and K.D. Park, 2001. An immunohistochemical study on the endocrine cells in the alimentary tract of the red-eared slider (Trachemys scripta elegans). Anat. Histol. Embryol., 30: 33-39.

Patel, Y.C. and S. Reichlin, 1978. Somatostatin in hypothalamus, extrahypothalamic brain and peripheral tissues of the rat. Endocrinology, 102: 523-530.

Patel, Y.C., 1999. Somatostatin and its receptor family. Front. Neuroendocrinol., 20: 157-198.

Polak, J.M. and S.R. Bloom, 1986. Somatostatin localization in tissues. Scand J. Gastroenterol., 119: 11-21.

Pyarokhil, A.H., M. Ishihara, M. Sasaki and N. Kitamura, 2012. Immunohistochemical study on the ontogenetic development of the regional distribution of peptide YY, pancreatic polypeptide, and glucagon-like peptide 1 endocrine cells in bovine gastrointestinal tract. Regul. Pept., 175: 15-20.

Saito, T., J. Yamada, N. Kitamura and T. Yamashita, 1989. An immunohistochemical study on the distribution of endocrine cells in the gastrointestinal tract of domestic pigeon, (Columba livia var domestica). Zeitschrift fur Mikroskopisch Anatomische Forschung, 103: 237-246.

Trandaburu, T. and F. Nurnberger, 1995. Somatostatinimmunoreactive cell in the gastrointestinal tract of the frog Rana esculenta. Cell Tissue Res., 279: 437-440.

Van Op den Bosch, J., D. Adriaensen, L. van Nassauw and J.P. Timmermans, 2009. The role(s) of somatostatin, structurally related peptides and somatostatin receptors in the gastrointestinal tract: A review. Regul. Pept., 156: 1-8.

Viollet, C., G. Lepousez, C. Loudes, C. Videau, A. Simon and J. Epelbaum, 2008. Somatostatinergic systems in brain: Networks and functions. Mol. Cell Endocrinol., 286: $75-87$. 
Vockel, M., Pollok S., U. Breitenbach, I. Ridderbusch, H.J. Kreienkamp and J.M. Brandner, 2011. Somatostatin inhibits cell migration and reduces cell counts of human keratinocytes and delays epidermal wound healing in an Ex vivo wound model. PLoS One, Vol. 6. 10.1371/journal.pone.0019740.

Wang, J.X. and K.M. Peng, 2008. Developmental morphology of the small intestine of African ostrich chicks. Poult. Sci., 87: 2629-2635.
Yamanaka, Y., J. Yamada, N. Kitamura and T. Yamashita, 1989. An immunohistochemical study on the distribution of endocrine cells in the chicken gastrointestinal tract. Z. Mikrosk. Anatomische Forsch., 103: 437-446.

Yang, Q., G. Lian and X. Gong, 2007. Enhancement of mucosal immune responses in chickens by oral administration of cysteamine. Poult. Sci., 86: 1323-1328. 